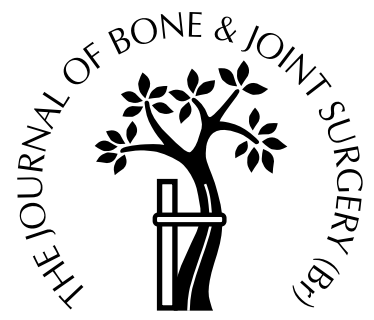

\title{
Serrated W/M osteotomy
}

\section{RESULTS USING A NEW TECHNIQUE FOR THE CORRECTION OF INFANTILE TIBIA VARA}

\author{
S. Hayek, E. Segev, E. Ezra, F. Lokiec, S. Wientroub \\ From the Dana Children's Hospital, Tel Aviv Medical Centre and the Sackler School of \\ Medicine, Tel Aviv University, Israel
}

T he conventional osteotomies used to treat infantile tibia vara (Blount's disease) may require internal fixation and its subsequent removal. These techniques, which carry the risk of traction injury, and potential problems of stability and consolidation, do not always succeed in correcting the rotational deformity which accompanies the angular deformity.

We have used a new surgical approach, the serrated W/M osteotomy of the proximal tibia, to correct infantile tibia vara in 15 knees of 11 patients. We present the results in 13 knees of nine patients who have been followed up for a mean of eight years. The mean angular correction achieved after operation was $18 \pm 5.8^{\circ}$. The mean femorotibial shaft angle was corrected from $14.2 \pm 3.7^{\circ}$ of varus to $4.6 \pm 4.4^{\circ}$ of valgus. At the last follow-up, the mean angular correction had reduced to $1.3 \pm 4.9^{\circ}$ of valgus without compromising the rotational correction and the overall good clinical results. All the patients and parents were satisfied, rating the result as excellent or good. There were no major postoperative complications and no reoperations. Eight patients were free from pain and able to perform physical activities suitable for their age. One complained of occasional pain. This procedure has the advantage of allowing both angular and rotational correction with a high degree of success without the need for internal fixation.

J Bone Joint Surg [Br] 2000;82-B:1026-9.

Received 24 August 1999; Accepted after revision 17 February 2000

Many methods have been described for the treatment of infantile tibia vara (Blount's disease), the most common of which is proximal tibial osteotomy. ${ }^{1-6}$ Opening- and clos-

S. Hayek, MD, Senior Orthopaedic Surgeon

E. Segev, MD, Senior Orthopaedic Surgeon

E. Ezra, MD, Senior Deputy Director

F. Lokiec, MD, Lecturer in Orthopaedics

S. Wientroub, MD, Professor, Incumbent, The Goldberg Family Chair in Paediatric Surgery

Department of Pediatric Orthopaedics, Dana Children's Hospital, Tel Aviv

Medical Centre, 6 Weizmann Street, Tel Aviv, Israel 62439.

Correspondence should be sent to Professor S. Wientroub.

(C)2000 British Editorial Society of Bone and Joint Surgery 0301-620X/00/710507 \$2.00

1026 ing-wedge osteotomies are generally used, together with dome and Chevron-type osteotomies. ${ }^{7,8}$ Conventional osteotomies usually require internal fixation and its subsequent removal. ${ }^{2}$ Opening-wedge osteotomy carries the risk of a traction injury and has potential problems of stability and consolidation. ${ }^{1}$ Moreover, these techniques do not always successfully correct the rotational deformity which accompanies the angular deformity in this condition.

We have reviewed our experience with the serrated W/M osteotomy procedure, first described in 1995 . $^{9}$ This technique enables simultaneous correction of the angular and rotational deformities of the tibia to be made without the necessity for rigid internal fixation. It also allows postoperative adjustment of any residual deformity if necessary. We now have a longer follow-up of these cases.

\section{Patients and Methods}

From 1980 to 1996, we performed 15 serrated W/M proximal tibial osteotomies in 11 children, two boys and nine girls, with infantile Blount's disease. Four patients had bilateral procedures. Their mean age at the time of operation was three years and six months (two years and four months to five years and one month). All were asked to return for re-evaluation, but only nine (13 tibiae) were available for follow-up. The mean follow-up was $8.0 \pm 4.2$ years $(2.5$ to 17$)$.

The patients were examined clinically and radiologically. They or their parents were asked to rate their current level of function, the presence and extent of pain, overall satisfaction with the operation, and if they had been or were still seeking any further treatment.

The final outcome at the last follow-up was rated by the attending surgeon using a grading system of 'good', 'fair' and 'poor' as described by Schoenecker et al. ${ }^{\text {I0 }} \mathrm{A}$ normal axis was considered to have less than $6^{\circ}$ of varus and less than $3^{\circ}$ of valgus, according to Henderson, Kemp and Green. $^{11}$

Operative technique. The technique has been described earlier. ${ }^{9}$ Briefly, preoperative planning includes measuring the tibiofemoral angle clinically and from standing anteroposterior (AP) radiographs of both lower limbs. The amount of angular correction needed to achieve $5^{\circ}$ to $7^{\circ}$ of valgus alignment is then calculated. The desired amount of 


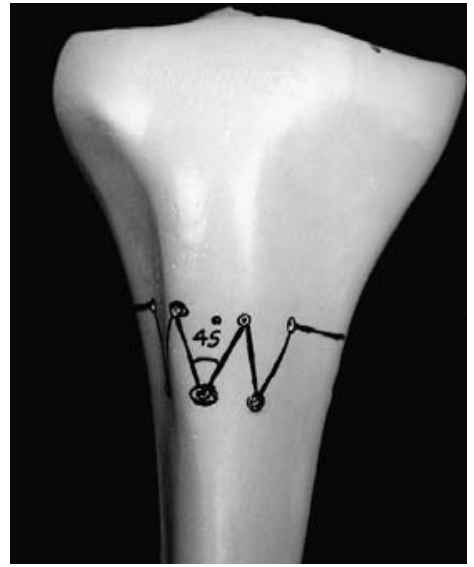

Fig. 1a

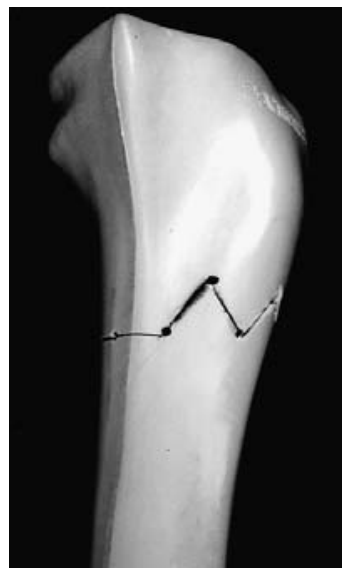

Fig. 1b
Photographs showing a model of the proximal tibia with the planning of drill holes and the serrated W/M osteotomy.

rotational correction is assessed clinically. The width of the longitudinal segments of the serration is measured precisely according to the equation:

$$
\mathrm{L}=0.017 \times \mathrm{Q} \times \mathrm{R}
$$

where $\mathrm{Q}$ is the desired angle of correction in degrees, $\mathrm{R}$ is the radius of the bone at the planned osteotomy site measured on a plain radiograph, and $\mathrm{L}$ is the width of the longitudinal segments which form the base of the triangular serration. $^{9,12}$

With the patient in the supine position the skin of both lower limbs is prepared and draped free to allow visual verification of position. After a tourniquet has been applied, a lateral compartment fasciotomy and a fibular osteotomy are performed at the middle of the fibula followed by a preventive anterior compartment fasciotomy through an

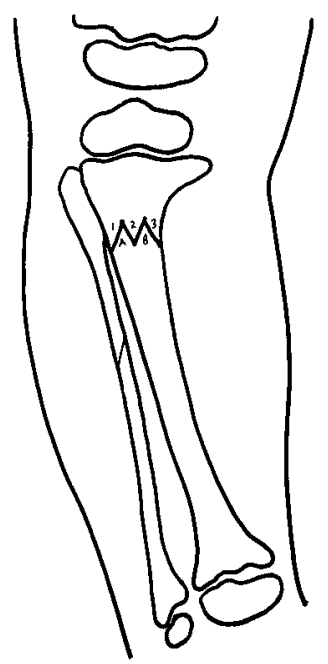

Fig. 2a

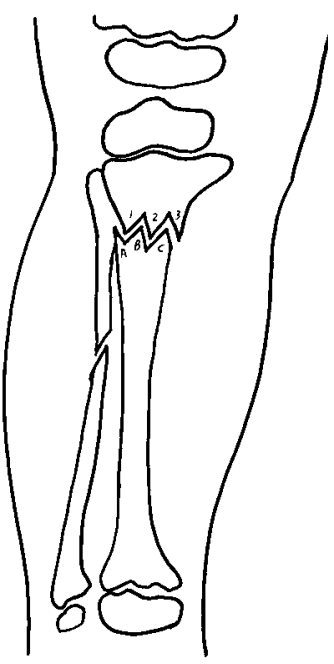

Fig. 2b
Diagrams showing the operation. Figure $2 \mathrm{a}-\mathrm{A}$ ' $\mathrm{W}$ ' or ' $\mathrm{M}$ ' shape is marked on the proximal tibia by drill holes which are connected by an osteotome to complete the osteotomy. Figure $2 b-$ The serrations are disengaged while the distal tibia is derotated and then re-engaged in the corrected position. Note the numeral and letter markings showing the displacement of the serrations. anterior vertical incision $5 \mathrm{~cm}$ long. The proximal shaft of the tibia is then exposed subperiosteally just below the tibial tuberosity. A ' $\mathrm{W}$ ' or ' $\mathrm{M}$ ' shape is marked by preplanned drill holes, and an osteotome is used to connect the marks and to complete the osteotomy posteriorly (Fig. 1). The serrations are disengaged while the tibia is derotated as desired and then re-engaged in the corrected position, thus preventing malalignment. An appropriate valgus position is achieved by dovetailing the teeth in the desired direction (Fig. 2). A Kirschner wire is sometimes added for temporary fixation until a long-leg cast is applied with $90^{\circ}$ of knee flexion to control rotation and to prevent weightbearing even accidentally. The final alignment is confirmed by radiography (Fig. 3). After six weeks a straight, long-leg cast is applied. This is worn for another six weeks, and weight-bearing is then allowed.

\section{Results}

There were no major complications. The mean varus deformity measured preoperatively on plain radiographs was a tibiofemoral angle of $14.2 \pm 3.7^{\circ}$. The mean metaphyseal-diaphyseal angle (MDA), as described by Levine and Drennan, ${ }^{13}$ was $15.6 \pm 5.5^{\circ}$. Two patients were in stage II, eight in stage III and three in stage IV of the Langenskiöld ${ }^{14}$ classification of the disease (Table I).

The mean angular correction after surgery was $18 \pm$ $5.8^{\circ}$, resulting in a mean femorotibial angle of $4.6 \pm 3.5^{\circ}$ of valgus. The mean MDA measured $7.7 \pm 3.5^{\circ}$. At a mean follow-up of 2.8 years from operation, the femorotibial angle was $4.2 \pm 4.4^{\circ}$ of valgus and this had decreased radiologically to $1.4 \pm 4.2^{\circ}$ of valgus at the last review. The MDA was $7.8 \pm 6.6^{\circ}$ at the last follow-up. The mean clinical measurement of the knee was $1.3 \pm 4.9^{\circ}$

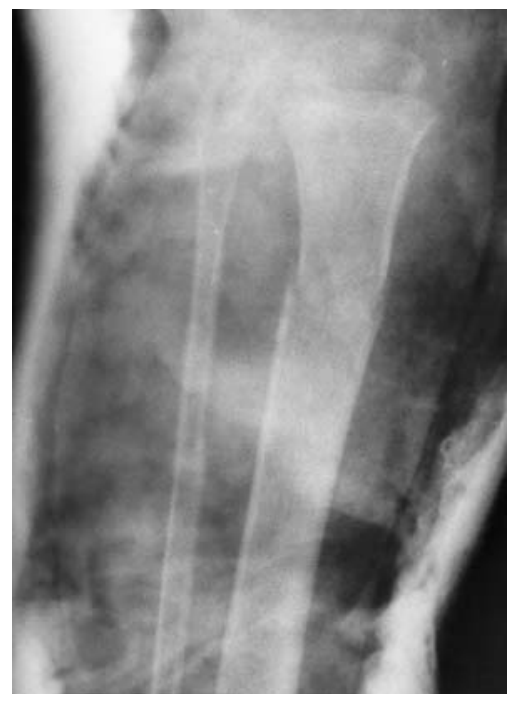

Fig. 3

An immediate postoperative anteroposterior (AP) radiograph showing the position of the tibia after the re-engagement of the serrations. 
Table I. Details of nine patients who underwent serrated W/M osteotomy for the correction of infantile tibia vara. Negative values are varus and positive values are valgus. Positive values represent external rotation

\begin{tabular}{|c|c|c|c|c|c|c|c|c|c|}
\hline \multirow[b]{2}{*}{ Case } & \multirow{2}{*}{$\begin{array}{l}\text { Age at } \\
\text { operation } \\
\text { (yr) }\end{array}$} & \multirow{2}{*}{$\begin{array}{l}\text { Langenskiöld } \\
\text { stage }\end{array}$} & \multicolumn{2}{|c|}{$\underline{\text { TFS }} *$ angle $\left(^{\circ}\right)$} & \multirow{2}{*}{$\begin{array}{l}\text { Time to mid- } \\
\text { term follow-up } \\
(y r)\end{array}$} & \multirow{2}{*}{$\begin{array}{l}\text { Mid-term } \\
\text { follow-up } \\
\text { angle }\left({ }^{\circ}\right)^{*}\end{array}$} & \multirow{2}{*}{$\begin{array}{l}\text { Time to last } \\
\text { follow-up } \\
(\mathrm{yr})\end{array}$} & \multirow{2}{*}{$\begin{array}{l}\text { Last follow-up } \\
\text { angle }\left({ }^{\circ}\right)^{*}\end{array}$} & \multirow[b]{2}{*}{ TFA $\left({ }^{\circ}\right) \dagger$} \\
\hline & & & Preop & Postop & & & & & \\
\hline 1 & 4.2 & IV & -20 & 10 & NA & & 17 & 10 & +5 \\
\hline 1 & & III & -14 & 8 & & & & 6 & 0 \\
\hline 2 & 3 & II & -10 & 8 & 6 & 7 & 12 & -2 & +15 \\
\hline 2 & & III & -15 & 2 & & 0 & & 0 & +20 \\
\hline 3 & 4.5 & IV & -15 & 5 & 1 & 6 & 2.7 & -5 & 0 \\
\hline 4 & 3.5 & III & -8 & -2 & 4 & -5 & 5.75 & 3 & +10 \\
\hline 4 & & III & -10 & 0 & & 0 & & 3 & +10 \\
\hline 5 & 3 & IV & -14 & 2 & 7 & 4 & 8.25 & 0 & +20 \\
\hline 6 & 3 & III & -14 & 8 & 3 & 4 & 4.75 & -5 & +10 \\
\hline 7 & 5.1 & III & -10 & 8 & 1 & 10 & 2.5 & 0 & +10 \\
\hline 8 & 2.8 & III & -20 & 5 & 1 & 8 & 8 & 6 & +5 \\
\hline 8 & & II & -18 & 3 & & 10 & & 0 & 0 \\
\hline 9 & 3.5 & III & -16 & 3 & 2 & 2 & 11 & 2 & 0 \\
\hline
\end{tabular}

* tibiofemoral shaft

$\dagger$ thigh foot angle

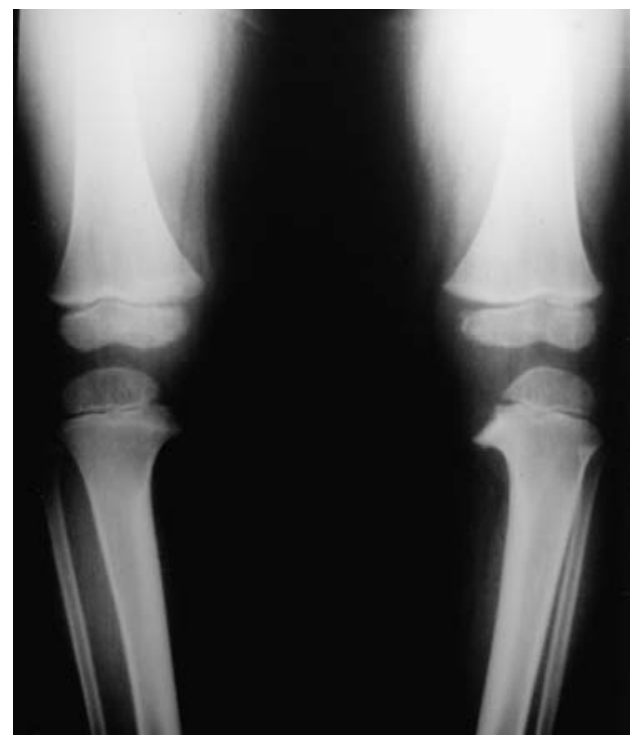

Fig. $4 \mathrm{a}$

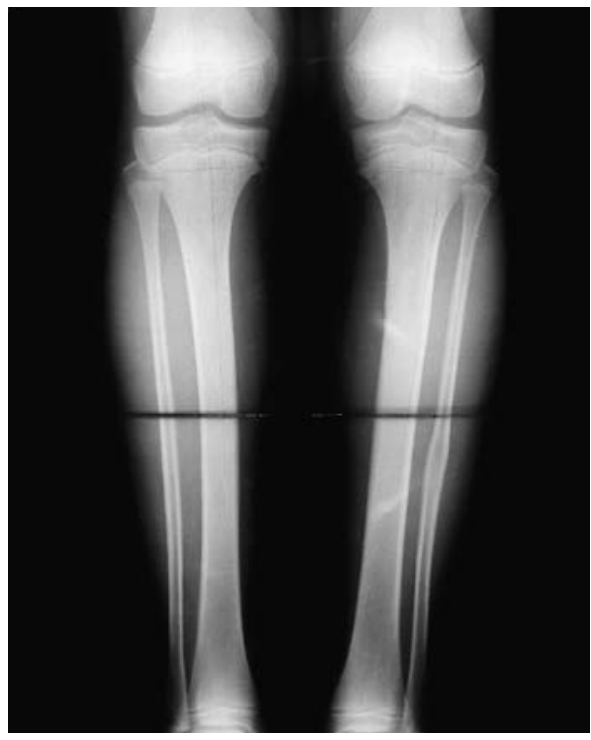

Fig. 4b
Case 3. AP radiographs showing a) the preoperative status at age two years, ten months and b) at age 11 years after serrated W/M osteotomy on the left leg. of valgus, and the thigh-foot angle, for evaluation of the rotational correction, was $7.7 \pm 7.2^{\circ}$. There was a residual varus angulation of the knees in four legs of three patients but all had varus angles which were within the normal range (Table I). One of these patients (case 3) suffered occasional pain and had a medial tibial epiphyseal slope of $15^{\circ}$. This was considered to be a fair surgical result. There was overcorrection (to $6^{\circ}$ and $10^{\circ}$ ) in three knees of two patients. One (case 1) had occasional pain and was considered a fair surgical result. The other (case 8 ) had a valgus tibiofemoral angle of $6^{\circ}$ with no other abnormality, but was nevertheless considered a fair result because of the overcorrection. Using Schoenecker's criteria for grading the results, nine knees had good and four fair results at the final follow-up. Further operation was not required in any case nor were there any significant complications after surgery (Fig. 4). Three patients have reached skeletal maturity and have maintained their correction.

All the children and parents considered the results of the operation and the cosmetic appearance to be excellent or good. At the last follow-up, seven patients stated that they had achieved levels of activity normal for their age. One had some difficulties in sports activities and one was limited in his normal activities because of occasional pain.

\section{Discussion}

The W/M serrated osteotomy enables correction of infantile tibia vara to be made without the need for internal fixation. It allows correction of all aspects of the deformity while preserving length, restoring joint alignment and preventing recurrence. $^{8}$

The natural history of untreated infantile Blount's disease is not well documented, but spontaneous resolution of the 
varus deformity is rare. ${ }^{4,15}$ However, Ingvarsson et $\mathrm{al}^{16}$ stated that only one-third of all untreated patients with infantile Blount's disease will have a straight leg without arthritis at the age of 40 years. There are several published studies on early osteoarthritis in untreated genu varum. Zayer ${ }^{15}$ concluded that the predisposition to osteoarthritis was not in direct relation to the degree of varus deformity. Hofmann, Jones and Herring ${ }^{17}$ found that $37 \%$ of the knees in their study were asymptomatic although most had early degenerative arthritis, but Doyle, Volk and Smith ${ }^{18}$ noted that $68 \%$ of their patients were asymptomatic.

There are few reports on the long-term follow-up of patients with infantile Blount's disease treated by operation. Hofmann et $\mathrm{al}^{17}$ and Doyle et $\mathrm{al}^{18}$ followed such patients for over 20 years. Doyle's group concluded that those with a single osteotomy had a significantly better result than patients who needed reoperation. ${ }^{18}$ Recurrence of deformity correlated with the development of late symptoms. No correlation was found between the degree of correction after operation and the final result at follow-up. The preferred timing for tibial osteotomies is as soon as it is clear that the deformity is not correcting spontaneously and before the age of four years, thus minimising the rate of recurrence and of late complications. 4,19

In a retrospective study of 37 children with infantile tibia vara, Ferriter and Shapiro ${ }^{19}$ found a rate of recurrence of $57 \%$ and of complications of $13 \%$ in proximal tibial osteotomies performed in the metaphyseal region, including closing- or opening-wedge and dome osteotomies with internal fixation.

Laurencin et $\mathrm{al}^{3}$ described the results of an oblique, incomplete, closing-wedge, proximal, tibial osteotomy using fixation by a lateral tension plate on 18 tibiae. The advantage of this method is that no immobilisation in a cast is required, but overcorrection may occur due to fracture of the medial cortex, there is shortening of the limb and removal of the internal fixation is necessary.

Opening-wedge-type osteotomy, as described by Martin et $\mathrm{al}^{2}$ has the advantage of stable fixation and predictive alignment, but needs a more extensive dissection and a second operation. However, two of their patients required further operation to correct deformity and another with infantile Blount's disease needed distal tibial rotational osteotomy because of undercorrection of the internal tibial torsion.

The use of external fixation for stabilising osteotomies for tibia vara was described by Price et al. ${ }^{1}$ This procedure has the advantage of adjustability, early weight-bearing and the ability to lengthen the limb. Its disadvantages are a longer consolidation time, unsightly scars, and the need for expensive, complex devices. Complications of this method include pin-track infections and postoperative neurapraxia. This technique appears to be more suitable for the adolescent patient with Blount's disease, in which $82 \%$ had good results compared with only $69 \%$ in the group with infantile tibia vara.

We describe a series of 13 limbs with a mean follow-up of eight years. There were no major complications, no neurological problems and no postoperative infections. Of the 13 knees, nine $(69 \%)$ had a good result and four $(31 \%)$ a fair result at the final follow-up. The results are even more encouraging when patient satisfaction is taken into account. No reoperations were necessary. The results compare favourably with other reported surgical techniques.

Although we found some decline in the correction achieved in most cases, this had no bearing on the functional and subjective outcome. At the last follow-up, all patients had maintained the correction of their rotational alignment.

We conclude that the serrated W/M osteotomy is a useful technique for the correction of infantile tibia vara. It is precise and reliable, and has become our standard method for treating infantile Blount's disease.

No benefits in any form have been received or will be received from a commercial party related directly or indirectly to the subject of this article.

\section{References}

1. Price CT, Scott DS, Greenberg DA. Dynamic axial external fixation in the surgical treatment of tibia vara. $J$ Pediatr Orthop 1995; 15:236-43.

2. Martin SD, Moran MC, Martin TL, Burke SW. Proximal tibial osteotomy with compression plate fixation for tibia vara. J Pediatr Orthop 1994;14:619-22.

3. Laurencin CT, Ferriter PJ, Millis MB. Oblique proximal tibial osteotomy for the correction of tibia vara in the young. Clin Orthop 1996;327:218-24.

4. Bernstein RM, Moseley CF. Blount's disease. In: de Pablos J, ed. The immature knee. Barcelona: Biblio STM, 1988:88-108.

5. Johnston CE 2nd. Infantile tibia vara. Clin Orthop 1990;225:13-23.

6. Rab GT. Oblique tibial osteotomy for Blount's disease (tibia vara). $J$ Pediatr Orthop 1988;8:715-20.

7. Richardson EG. Miscellaneous non-traumatic disorders. In: Crenshaw AH, ed. Campbell's operative orthopaedics. 7th ed. St Louis; etc: CV Mosby, 1986:1005-88.

8. Staheli LT. The lower limb. In: Morrissy RT, ed. Pediatric orthopaedics. 3rd ed. Philadelphia: JB Lippincott, 1990:741-66.

9. Khermosh O, Wientroub S. Serrated (W\M) osteotomy: a new technique for simultaneous correction of angular and torsional deformity of the lower limb in children. $J$ Pediatr Orthop B 1995;4:204-8

10. Schoenecker PL, Meade WC, Pierron RL, Sheridan JJ, Capelli AM. Blount's disease: a retrospective review and recommendations for treatment. J Pediatr Orthop [Am] 1985;5-A:181-6.

11. Henderson RC, Kemp GJ, Green WB. Adolescent tibia vara: alternatives for operative treatment. J Bone Joint Surg [Am] 1992;74-A:342-50.

12. Crider RJ, Leber C. Accurate correction in rotational osteotomies. $J$ Pediatr Orthop 1987;7:468-71.

13. Levine AM, Drennan JC. Physiological bowing and tibia vara: the metaphyseal - diaphyseal angle in the measurement of bowleg deformities. J Bone Joint Surg [Am] 1982;64-A:1158-63.

14. Langenskiöld A. Tibia vara: a clinical review. Clin Orthop 1989;246: 195-207.

15. Zayer M. Osteoarthritis following Blount's disease. Int Orthop 1980;4:63-6.

16. Ingvarsson T, Hagglund G, Ramgren B, Jonsson K, Zayer M. Long-term results after infantile Blount's disease. J Pediatr Orthop B 1998;7:226-9.

17. Hofmann A, Jones RE, Herring JA. Blount's disease after skeletal maturity. J Bone Joint Surg [Am] 1982;64:1004-9.

18. Doyle BS, Volk AG, Smith CF. Infantile Blount disease: long term follow-up of surgically treated patients at skeletal maturity. J Pediatr Orthop 1996;16:469-76.

19. Ferriter $\mathbf{P}$, Shapiro $\mathbf{F}$. Infantile tibia vara: factors affecting outcome following proximal tibia osteotomy. J Pediatr Orthop 1987;7:1-7. 